\title{
PACKING AS PRACTICE: CREATIVE KNOWLEDGES THROUGH MATERIAL INTERACTIONS
}

\author{
KAYA BARRY \\ School of Communication and Creative Arts, Deakin University, Melbourne, Victoria, Australia
}

\begin{abstract}
Tourists are presented with a range of material and interpersonal interactions that often develop into collaborative and creative modes of knowledge production. There is a current push to acknowledge processes and experiences as forged through material relations, for which tourism processes present a range of examples. This article advocates that the study of tourism needs to take a postdisciplinary approach that merges practice and theory, using the process of packing a bag as the primary example. A rethinking of material relations presents affirmative, global, and nomadic encounters for a multitude of actors and situations. In the rigorous, daily process of packing, objects are transformed into fluid, malleable forms - as a mass of material that is being collaboratively negotiated. In this way, materially driven processes open up collective experiences that offer methods of creative knowledge production. Drawing on interviews and photographic documentation of tourists packing, this article demonstrates the potential for postdisciplinarity research that examines possibilities for collaborative forms of creative knowledge production.
\end{abstract}

Key words: Creative knowledge; Postdisciplinary; Collective action; Materiality

Introduction

Tourists experience a range of encounters with materials that in certain instances generate creative knowledges. In everyday tasks and procedures, creative and collaborative processes are developed and shared between tourists. A reconstitution of materiality within globalized tourism culture is required to investigate these interactions, necessarily merging practice and theory, as no one discipline or technique can adequately address the complexity of collective concerns. In an examination of the act of packing a bag for travel, I demonstrate a postdisciplinary approach to how materially driven experiences unfold in tourism scenarios. I suggest that material processes are necessarily developed by tourists in everyday actions, and these are used to generate alternative forms of knowledges that can be considered creative and collaborative. Materiality, in this vein, is used simultaneously as a process and concept, which transgresses its discursive origins. Further, the example of packing a bag will be 
used as an example of how tourists can be made aware of movements that are at times collaborative and communal, operating across an array of actors.

The aim of this discussion is to outline the many ways that tourism presents processes that draw from a range of perspectives in order to take into account an array of material experiences between humans and nonhumans. Starting with an overview of how tourism can be considered as one of the many forms of mobility that informs and influences our actions, I highlight the need for tourism studies to reconceptualize the role of material relations and what they indicate for our ability to negate within a mobile-global culture of tourism. Next, an examination of how these actions in tourism highlight the intersection of current explorations into materiality is considered from a range of disciplines. In doing so, this new emphasis on materialism demonstrates instances in tourism that require methods and techniques that move beyond disciplinary boundaries, harnessing experiences in the field and on the move. This is made evident through the daily material procedures that tourists undertake that are indicative of such mergers of practical "hands-on" engagements and conceptually driven ideals and expectations of tourism experiences. These actions blur the polarities of being stationary (i.e., "at home”) or mobile and traveling (i.e., "away”), thus creating a greater awareness of possibilities and movements with materials that can be beyond ourselves and beyond our own subjective individual decisions. Consequently, the merging of everyday with touristic processes compels postdisciplinary perspectives that embrace a merger of practice and theory, following the situation of study as it unfolds. Drawing from interviews with tourists and documentation of their packing activities will support my propositions.

This article deploys a process that moves beyond disciplinary boundaries of practice and theory and provides an example of the way a material approach may more adequately address complex tourism scenarios. It is not just a merger of techniques across disciplines; instead, this material approach congeals practical and theoretical influences, utilizing them as required for the specific line of inquiry. As a result, my approach tackles two issues simultaneously: (1) a reconceptualization of materiality as witnessed and experienced in tourism scenarios and (2) how this reworking of materially driven interactions - through not just metaphor but as a theoretical imperativereveals methodological and ontological concerns in tourism studies that shift past disciplinary confines. I adopt a postdisciplinary approach-drawing from my own experiences, interviews, and photographic documentation with fellow tourists staying in hostel accommodations ${ }^{1}$ and from an array of theory-to "unpack" the process of packing a bag. I highlight how postdisciplinarity research requires reflexive methodologies (Wolmark \& Gates-Stuart, 2004) that follow themes and lines of inquiry (Gregson, 2003; Sayer, 1999) to explore instances where collaborative experiences and creative knowledges emerge.

An anecdote of a scene that I witnessed in a hostel provides a good starting point and suggests the scope and complexity of the issues on which I have chosen to focus. I had just checked into the hostel, located my 10-bed mixed dormitory room, and I opened the door to find two people sitting on a large suitcase while another frantically shoved in items of clothing through the open seam on the side. "His airport shuttle leaves in 20 minutes," one of the guys who was half kneeling, half sitting on top of the suitcase said to me, as if this could explain why he was perched precariously on top of somebody else's overflowing suitcase. In this instance, three previously unacquainted persons plus myself became bound together in action. The emphasis of material process, of achieving the "packed bag" as end goal, highlights a moment in tourism where procedural tendencies and expectations (i.e., notions of personal space, social etiquette) are necessarily overturned in favor of haptic, collaborative, and material interactions.

It is important to sketch out the general experience of a hostel accommodation. Dormitory-style hostels present a hive of activity often similar to this experience I had. Numerous people are in close proximity to each other, sleeping in bunk beds and sharing bathroom facilities. Bunk beds are strewn with coats, hand-washed clothes, and assorted personal items. There is almost always one person suffering terribly from jetlag, asleep on his or her bed in the middle of the day, while everyone else tip toes around trying to carry out their daily activities of washing, dressing, planning, and packing. In the corner you will find someone frantically sorting through his or her bag, as his or her belongings, including underwear, are upturned from the bag 
and out on display for the entire dormitory occupants to see. The process of packing and these fleeting, often heightened moments of intense material interactions become the everyday experience for people who are traveling. Packing a bag reveals an intersection of a number of concerns-materiality, creativity, and collaboration-through a specific example of material conditions and interactions that are engaged during travel.

In the above example, and in the several that follow, a materially driven experience emerges that begins to overcome normal human-nonhuman boundaries of interaction. The material processes are considered here to be a range of activities and procedures, from subtle interactions that are mediated through materials, architectures, and objects, to the specific focus of this examination-the act of packing a bag. I argue that the example of packing unveils interactions that are movements of materials-between bodies, objects, and encompassing an array of human-nonhuman actors. The emphasis on actors as both human and nonhuman throughout this inquiry is a reminder that multiplicities of actors are moving in complex and interrelated ways and, as such, "cannot be captured and understood by those residing in single disciplines" (Coles, Hall, \& Duval, 2009, pp. 90-91). Embracing a postdisciplinary approach, I unpack and interpret the significance of these actions between humans and nonhumans, emphasizing the creative forms of knowledge being generated. I use the phrase creative knowledges as an attempt to pinpoint, if only momentarily, the many performative, embodied, and collaborative methods that cohere within such encounters. Consequently, I expand not only the modes of knowledge that inform my postdisciplinary approach to research but also the knowledges that tourists partake in as they negotiate increasingly entangled interactions in daily processes. The result is that the cohesion of many methods into specific actions presents postdisciplinary approaches for the study and practice of the many movements within tourist experiences.

\section{Tourism as a Process}

There is an increasing prevalence to recognize, encompass, and expand on how experiential and creative knowledges are generated by tourism and mobilities. Although there is strong emphasis on the importance of the interrelations that increasing mobilities bring to a global society (Sheller \& Urry, 2004; Urry, 2003, 2012), the role of materiality and the relational aspects of tourism alongside everyday practices are still fairly underexamined. There are calls to embrace postdisciplinary approaches and provide deeper investigations into how tourism presents opportunities for alternative forms of knowledge (Büscher \& Cruickshank, 2009; Coles et al., 2009; Gill, 2012; Hollinshead, 2010; Hollinshead \& Ivanova, 2013; Sayer, 1999; Wolmark \& GatesStuart, 2004). The proposition of "tourism as a knowing practice” (Crouch, 2004, p. 90) as well as the multiplicity and relational aspects of each individual tourist experience (van der Duim, Ren, \& Jóhannesson, 2013) reinforce this urgency for a debate about the processes that are undertaken by both tourists and tourism researchers. Debate in the study of tourism (as well as in the fields of geography and mobilities) demonstrates the often contradictory positions of attempting to maintain a definition of one's own field of research while increasing the awareness and reflexivity in research methodologies (Gill, 2012; Gregson, 2003). Following themes, issues, and ideas have been suggested as an appropriate way to research tourism practices, thus advancing the research without restricting it to disciplinary styles.

Considering tourism as a process requires close scrutiny of how knowledges are produced and strategies developed as we travel (either corporeally or intellectually). To this end, investigating the role of materials and the resulting materially driven interactions occurring in-transit provides ways to better understand this increasing mobility and to emphasize acceptance of nomadic forms of subjects. An examination of material encounters across human and nonhuman actors may lead to new ontological and methodological approaches (Dolphijn \& van der Tuin, 2011) and compels postdisciplinary perspectives. Understanding the processes within tourism that move beyond traditional notions of individualized subjectivity, and examining the possibilities that can arise in the current mobile-global culture of tourism, will reveal how these expanded processes can afford creative and collaborative engagements.

The processes that are undertaken every day during tourism indicate an assortment of material 
interactions. In the most obvious instance, materially driven processes are tactile encounters where bodies and material substances come into proximity and contact with each other (for discussion on materialbased creative research, see Barrett \& Bolt, 2007; also see Carter, 2004, for a proposal of "material thinking”). In addition, tourism processes that open our awareness to aesthetic and relational qualities of materials-as sensual, embodied, or processual interactions - provide foundations for the decisions, motivations, and actions that are undertaken by both individual tourists and also within the increasingly globalized culture of tourism. These various material encounters motivate further experiences across a range of actors. The manner in which these various understandings and instances of material interactions are understood affects the way tourism values the role of everyday material encounters in mobile situations, suggesting that knowledge arises through a range of actions rather than being bound to one method or discipline.

Although there have been many notable studies that present "tourism as a practice" (Crang, 1999, p. 238; Crouch, 2004; Haldrup \& Larsen, 2010; Lean, 2012; Sheller \& Urry, 2004; Urry, 2003, 2012; Urry \& Larsen, 2011), the question of how these practices are carried out is often centered on the individual tourist's subjective decisions. Instead, the examination of material actors (nonhumans) and the roles and agency that they hold within tourism processes compels further inquiry into how and why practices that are inherently material are carried out. Yet, it is the everyday tourist processes, often as materially driven actions, that can direct us toward notions of creativity and that are arguably best explored through a postdisciplinary lens.

Tourist habits may become a source of creative knowledges where everyday interactions are utilized to gain creative experiences and insights. My notion of creative knowledges encompasses a range of processes surrounding how knowledge is produced, acquired, and transmitted. In tourism scenarios, such processes might be those that aid in situating ourselves-performing with and in given places and events - or processes that develop through aesthetic considerations, particularly the attention to material or spatial qualities of objects, places, and actions. These processes manifest in the obvious tourist activities: exploration of the destination, organized tours, photography, themed attractions, museums, galleries, bars, and so forth. However, it is more indicative to observe processes in the daily tasks of packing a bag, sorting through personal items (discarding, lending, acquiring), cooking, washing, conversing, sleeping, and so forth to find the manifestations of material processes. My understanding of creative knowledge production and transmission arises from creative arts research, where practice and theory are inseparable (Barrett \& Bolt, 2007; Carter, 2004). Knowledge and creativity, in this sense, are by no means fixed; rather, they are fluid and relational, forming part of the heterogeneous qualities of the ways in which we navigate through and establish relationships. Creative and processual methods encourage a breach of traditional disciplinary techniques, making "hybrid forms of knowledge production" possible (Hollinshead \& Ivanova, 2013, p. 55).

The understanding of knowledge as formed through actions aligns with analysis inspired by actor-network theory, where actions undertaken assist in harnessing the potential of multiplicities in every encounter (Mol \& Law, 1994, 2007; van der Duim, 2007; van der Duim et al., 2013). These oscillatory movements of experience, from localized production in an individual's subjective actions to a broader conception of global multiplicities, provide a relational framework in which, as Latour (2007, p. 172) noted, the collective emerges. Latour's (1996, p. 231) proposition of collective action, focused through materially driven interactions, allows us to understand how connections are formed and how such encounters produce new connections. Thus, by focusing on one specific example of interaction-the process of packing a bag-the relations and applications of such an event can be teased out in order to present ways that "philosophical and empirical investigations into the ontological condition of tourism" can be undertaken (van der Duim et al., 2013, p. 13). In the following examination of packing a bag, I draw together an assortment of theoretical perspectives, which support the interview data, observations, and my own experiences in a postdisciplinary entanglement of practice and theory.

In order to discuss the role that material encounters play in tourist's experiences, the processes undertaken during travel must be examined. Each 
transition and destination presents an array of new relations that require a repositioning of the tourist's actions and the priorities to enact the required processes. The example of packing a bag highlights a range of interrelated processes - for instance, searching for an item within the bag at an airport check-in counter or trying to sort dirty from clean clothes in a dormitory room. Relations emerge through a "convoluted network with a multiplicity of highly diverse dates, places and people" (Latour, 1996, p. 231). These emergent actions compose propositions for material encounters through interaction between actors.

Because we learn by doing and repeated doing becomes a practice (Marchand, 2010, p. 7), we are enacting processes and new relationships with/in the world (Mol, 2002, pp. 32-33). As Marchand (2010) posited, "becoming knowledgeable is not a matter of assembling information . . . but rather knowledge is formed in everyday activities and knowing is conterminous with our movement through the world" (p. 15, ). Knowing through experience reveals the mechanisms (O'Sullivan, 2006, p. 44) that allow orientation and adjustment to our everyday movements and interactions. As Wolmark and Gates-Stuart (2004) pointed out, "conceptualising both knowledge and imagination as situated" requires an awareness of "intersections between seemingly discrete practices and forms of knowledge” (p. 5). Knowing through practice is arguably integral to a postdisciplinary methodology, as connections are unfolded through experiences, opening up new avenues for exploration.

Practices that foster interaction between actors involve methods of performativity, embodiment/ bodily encounter, and sensory attention (Drummond, Keane, \& West, 2012). Often these encounters are social, sometimes they are playful (Sheller \& Urry, 2004; Thrift, 2007), and they are usually strenuous. These processes are never isolated to the individual tourist; they are movements that are enacted through the vast network of actors, both human and nonhuman. These performances are often materially driven, as "tourists are always depended on nonhumans . . . and their material agencies” (Gren \& Huijbens, 2012, p. 162). As we explore and negotiate daily tasks, we (as an assemblage of humans and nonhumans) generate "activity with immense affective significance” (Thrift, 2007, p. 7).
Although fleeting, such encounters begin to open up a realm of modes of understanding and thinking through our everyday movements and through multiplicities of both local and global scales. Viewing this process as a creative practice brings forth the "ability to alter the ways in which we perceive things in the world" through materialized forms, transforming through practice our attention toward “affective perceptual experiences” (Colman, 2007, p. 72). When we are open to a multiplicity of potential events and experiences that arise during travel, the notion of creativity, in this understanding, is beyond disciplinary definitions and constraints.

To return to my earlier example of the three people packing one suitcase, there are personal, social, and material boundaries that are being redefined through such actions. Questions of personal space, of interaction and social cues, as well as the inherent materiality of the actions compel further scrutiny of this "hands-on" collaboration. A new materialist understanding of these practices is an assertion that all actors-human and nonhuman-are "composed of-or are reducible to-matter, material forces or physical processes" (Stack, cited in Bolt, 2013, p. 2). The resurgence of interest in materialism foregrounds that all actors have agency and that it is distributed through interactions. New materialism emphasizes that the material composition of actors-such as the body packing, the suitcase, or of the events that constitute tourism processesmay be regarded as a vital element in each action. Materially driven processes are integral part of "knowledge-growing" (Ingold, 2010, p. 116) and aid our understanding of where and how we situate ourselves in relation to the world. Through these daily practices, an open and sustainable level of interaction between an array of actors is generated. The example of communal packing gives prominence to a destabilizing of sociocultural expectations through processed-based interactions. This is just one example of a "truly 'embodied' discover[y] about the temporal, social, and physical processes that are inseparable from acts of learning and communicating knowledge” (Marchand, 2010, p. 7).

Creativity provides insights into the possibilities that these everyday encounters may take. Massumi (2008) advocated that "we always see relationally and processually in this way, but art makes us see that we see this way” (p. 7). If only momentarily, 
we think about the process of packing as an everevolving performance artwork that helps to actualize the possibilities for affective experiences that challenge our presumptions. Packing a bag is a tricky task to negotiate. Simply locating one item within the bag presents a mammoth task of dismantling carefully placed items, decanting these onto the floor, onto the bed, or into spare hands. The body flits in and around the bag-the zipper pulls tightly, catching the fabric. One item leaks, suddenly the clothes and the floor are covered in a soapy residue. A frenzy of complex movements occurs between the person packing, the items in the bag, the material of the bag itself, the surfaces of the architecture they are within, and the temporalspatio shifts occurring in that particular destination. These moments challenge our presumptions of our bodily limits and our ability to interact and collaborate with a realm of actors.

Reconceptualizing the role that materiality plays in tourism is a necessity in both ontological and methodological concerns (Dolphijn \& van der Tuin, 2011, p. 384). It is helpful to understand the recent revival of materiality (Barad, 2008; Barrett \& Bolt, 2007; Bolt, 2013; Braidotti, 2012; Dolphijn \& van der Tuin, 2011; Grosz, 2011; Haldrup \& Larsen, 2010; van der Duim et al., 2013) that transgresses discursive domains, assisting the examination of process-based encounters in tourism. By rethinking what is constituted as material, a creative and affirmative collaboration between bodies, objects, and environments emerges.

\section{Collective Unpacking}

In addition to my own practice of packing during a 2-month research trip, I interviewed fellow tourists in hostels about the ways in which they understand their own processes. Strategies of collating objects showed a process that transforms objective qualities into material concerns. The process of packing sees a transformation of objects away from singular forms toward a fluid mass of material that is being negotiated.

Of the 20 tourists I spoke with and photographed, 14 tourists said that they had a specific strategy for packing. Most evident was the strategy of collating objects with an intensified consideration of a range of material properties - the size, texture, density, weight, and so forth. Comments were made, such as "I try to keep it in order . . . my socks first, then my pants, and then . . . my T-shirts.” Another said they grouped clothing together, explaining that

$$
\begin{aligned}
& \text { underwear [goes] together in one bag . . . and then } \\
& \text { like T-shirts in one, and pants and sweatshirts in } \\
& \text { another . . . so that way it's all like, if I want to } \\
& \text { change my underwear or something I know where } \\
& \text { it is ... I keep them together. }
\end{aligned}
$$

Others grouped items on the basis of size and weight: "Shoes in the bottom, and big stuff in the bottom," one tourist explained. A common focus was on manipulating the materials to compress and combine things together. "I like to roll things up and it makes things a lot smaller," one remarked. Or as another person noted, everything is laid "flat across the bottom ... like building blocks.” The variations of descriptions and types of measurements usedthat is, weight, texture, substance, categories, and so forth-disclose the many different roles that objects take on in this process. Depending on the movements required, materials are regarded in a variety of different means, pointing toward a complexity of actions that revolve around the ways that material elements oscillate between singular forms and a fluid material array of actors that are in consultation with each other. What began to emerge from these interviews is that in the rigorous daily process of packing, objects are often no longer conceived as singular forms, but rather they transform into fluid, malleable substances, as a mass of material that is being negotiated.

The words that they used to describe the process are also indicative-terms such as "squish," "squeezing," and "stuffing"-indicating how each object was being transformed into a malleable form that could be adapted and integrated into a fluid mass of material in the process. This transformation of objects from single to multiple is in line with Law's (2002) acknowledgment that "the singularity of an object is precarious, uncertain and revisable” (p. 36). Alternatively, as I am proposing, this mode of experiencing materials through processual encounters reveals materiality in a fluid form, unfixed from specific representations and forms. Grosz (2005) also described how in certain circumstances, materials have the ability to shift between objective, solid representational forms and as malleable, fluid matter. 
Emerging "out of and as substance," things (material entities) have the ability, through their transgressive potential, to open our awareness to alternative modes of experience and sensation (Grosz, 2005, p. 133). These subtle material negotiations have the potential to create situations in which materials are so intensified that they have the potential to overcome their own material forms and constraints. This has a long history in the production and reception of art-in how the materials negate our response, relation, and interaction with them. Under certain conditions, these nomadic, processual movements and encounters could be something that is, to borrow Grosz's (2011) terms, "beyond the material" (p. 17) where matter is "not a thing but a doing, a congealing of agency" (Barad, 2008, p. 173). In other words, when relationships emerge that are beyond ourselves (as singular materially comprised entities), an increased awareness and sensing of communal movements occur. Necessarily overturning singular identities in favor of collective actions, this signals a shift in habitual processes and knowledges.

Communal movements are highlighted through a range of theoretical notions, such as Latour's (2007) "tracing of associations" (p. 5). This tracing is a performative process (Latour, 2007, p. 34) involving a gathering of diverse actors - material, spatial, and temporal- that are human and nonhuman, which allow an examination within matters of concern (Latour, 2007, pp. 87-120). This shift that Latour proposed-away from an emphasis on "fact" and toward issues that hold a "concern"requires a materialistic inquiry that overcomes generic boundaries and presumptions. Once again, demarcations of disciplinary techniques can restrict the manner in which we can articulate these issues. Instead, a study of tourist practices needs to shift across and through a range of approaches and propositions, seeing each investigation as a "holistic endeavour” (Büscher \& Cruickshank, 2009, p. 2). An assortment of perspectives in research facilitates a "freedom of movement as those whose actions [the researcher] wants to follow" arises (Latour, 2013, p. 31). Studies of tourism are too often bound to theories of signs and representationalism, and as Haldrup and Larsen (2010) suggested, this is reinforced through an understanding of performance that is isolated to humanistic experiences.
As Latour (2007) maintained, “any thing that does modify a state of affairs by making a difference is an actor" (p. 71).

Tourism presents a range of scenarios that blurs individualized and collective processes between actors. This occurs at both a macro- and microscale as we are increasingly required to possess adaptive and transformative nomadic abilities to situate ourselves in the flow of the global (Urry, 2003, p. 41). The proposition of becoming nomadic, as furthered in Braidotti's (2002, 2012) nomadic theory, is an adaptive process in which the boundaries of individual and collective subjectivities are never fixed. It is not an end point or goal; instead, as Braidotti (2012) explained, "becoming nomadic means that one learns to reinvent oneself, and one desires the self as a process of transformation. It's is about the desire for qualitative transformations, for flows and shifts of multiple desires" (p. 41). To be an actor in the global flow (Urry, 2003) is "ultimately collective" (Braidotti, 2012, p. 43). Within these fleeting experiences that tourists have, where they congeal with a range of nonhuman actors in material and creative encounters, the potential of becoming nomadic begins to emerge.

\section{Moving With Materials}

While packing, movements that blur the boundaries between the usual usages and arrangements of objects and bodies highlight how materiality can become nomadic, fluid, and relational. As one person recounted, “To get all my stuff in my bag I was like rolling on it and sitting on it and kicking it trying to get everything to squish in.” Although subtle, similar examples are frequent in packing, inducing alternative ways that tourists move with their material belongings. The materials are constantly being renegotiated and assessed-whether they are useful, necessary, fragile, prone to leakage, and so forth. The roles of each material object and the expectations of the person packing are constantly being negotiated as he or she moves into proximity with the materials during the packing process. Nomadic and processual movements may be undertaken while packing, developing through rigorous interactions of the material objects and the bodies of the tourists. In addition to demonstrating nomadic movements, this example utilizes 
considerations of materially driven and collective experiences that bring together approaches that are postdisciplinary and focused on emergent and often unanticipated outcomes.

In the packing process, movements occur that increase our sense of something that is greater than ourselves and greater than the objects that are being packed. The intensive act of packing, where materials and bodies move together, allows us to consider a "nonunitary vision of the subject" (Braidotti, 2012, p. 3), as the boundaries of each material entity are momentarily blurred. Agency is no longer isolated to a singular or human subject, offering compositions of material agency that are entangled across actors. Manning (2009) called the movement between materials and bodies "the not-yet that composes the more-than-one” (p. 13). This is appropriate because movements are in the moment but are not quite actualized; they are influenced by existing structure yet do not determine where an action will come to rest or what the effects are going to be. The boundaries between the body and the bag are set into flux. It is here, in the flux, that we are made aware of the forces larger than ourselves as individuals and can sense the affective interactions playing out. In these moments, the notions of identity, individuality, and subjectivity are set askew and put into motion ready to be opened up, explored, and expanded.

Manning (2010) described how this affective movement of subjectivity is "across bodies, across resonances of life, some of them human, many of them non-human. Affect is what returns, not the subject” (p. 126). These philosophical propositions merge with and support the practical examples. For the tourists I interviewed, as well as in my own personal experiences, these moments are hard to pinpoint and are difficult to articulate, as often you feel immersed in this frenzied experience. As Latour (2007) reminded us, "action is not done under the full control of consciousness" (p. 44). The focus shifts from simply itemizing the objects within the bag, or selectively and consciously making movements, and it is at this point where potential for greater sensory awareness and creativity emerges.

It is this more-than potential that provides an increased sense of something greater than ourselves emerging through the objects that are being packed. These moments within packing bring forth a consideration of the potential to experience relationships beyond ourselves as individuals. These newly formed relationships breach individuality and present a collective of interactions that, if only momentarily, fuse the experience of the human-nonhuman. Arising through performativity, a collective emerges that leads to further participation and movement across categories of actors. The result is a situation that presents the ability to rethink the subject as a "collective entity" (Braidotti, 2008, p. 182). It creates movements through presumptions about individuals, places, and actions, linked through the intensified practices that are part of the everyday routine of tourists.

As part of the interview process, a series of photographs were taken that documented tourists unpacking and then repacking their bags. The photographs (see Figs. 1-4) indicate this collective action unfolding as a series of movements where material boundaries are reconfiguring through creative and embodied methods; the body moves with the bag. The photographs were taken with a longer exposure so as to highlight the movements of the bag, the objects, and the body. The movements in the photograph are presented as blurring, lingering moments that begin to indicate instances where the many subtle negotiations result in a congealing of the material of the body and the bag as the boundaries of the movements are ultimately stretched and warped. These movements are movements between the body and the bag in collaboration, observable as an object is placed inside the bag, and the hand and object move together in action. When the object is placed, the bag often shifts slightly, moving in response, setting the material boundaries into flux. The often frenzied attempts to unpack, sort, find, repack, and so forth reveal movements in which the materials - of the body, the bag, the objects-are moving in a manner where they are considered as greater than themselves, no longer singular entities but as a collaborative collective action, composed of matter and materials that flow with/in and between in the act unfolding.

Within this process of packing, material practices emerge revealing movements that are greater than ourselves, where materiality needs to be considered as more-than (Manning, 2010) a property of a singular entity. In these materially driven practices that reveal movements that are greater than the individual, attention must be given to the vast 


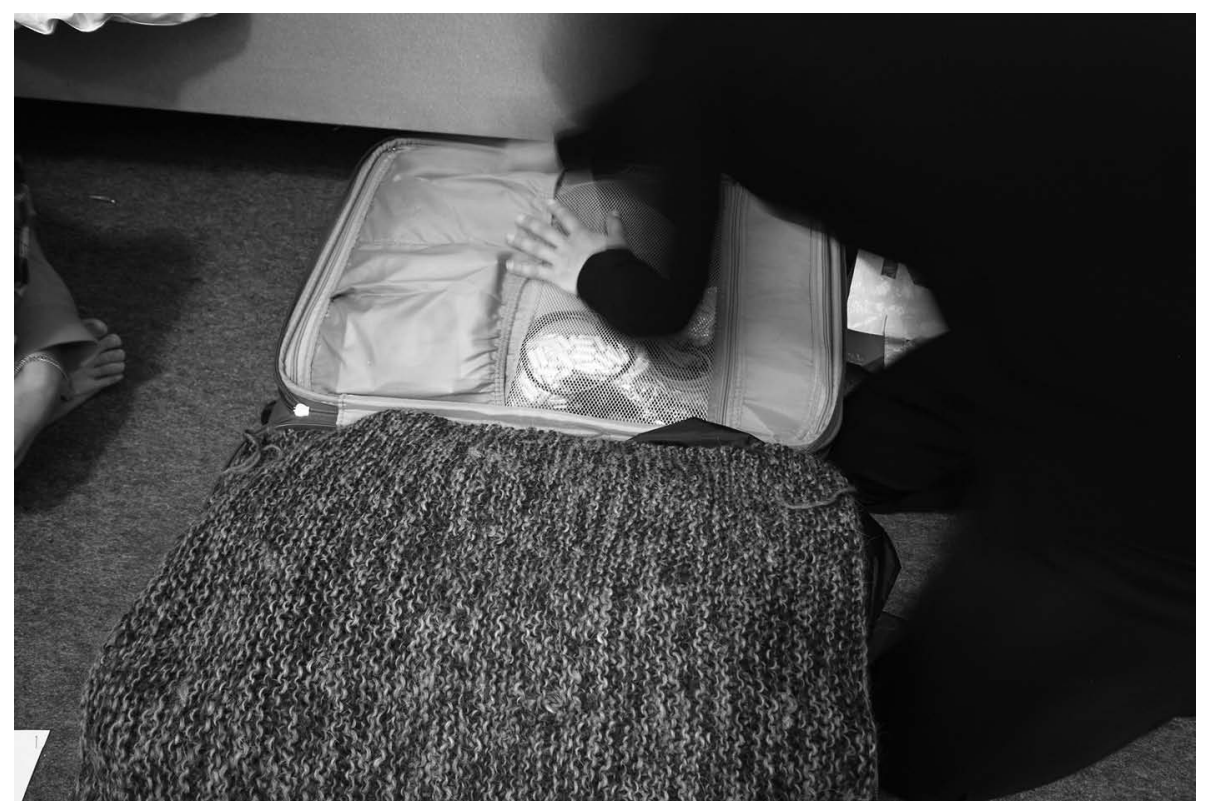

Figure 1. The body leans over the suitcase, pressing down on the bag in preparation to close.

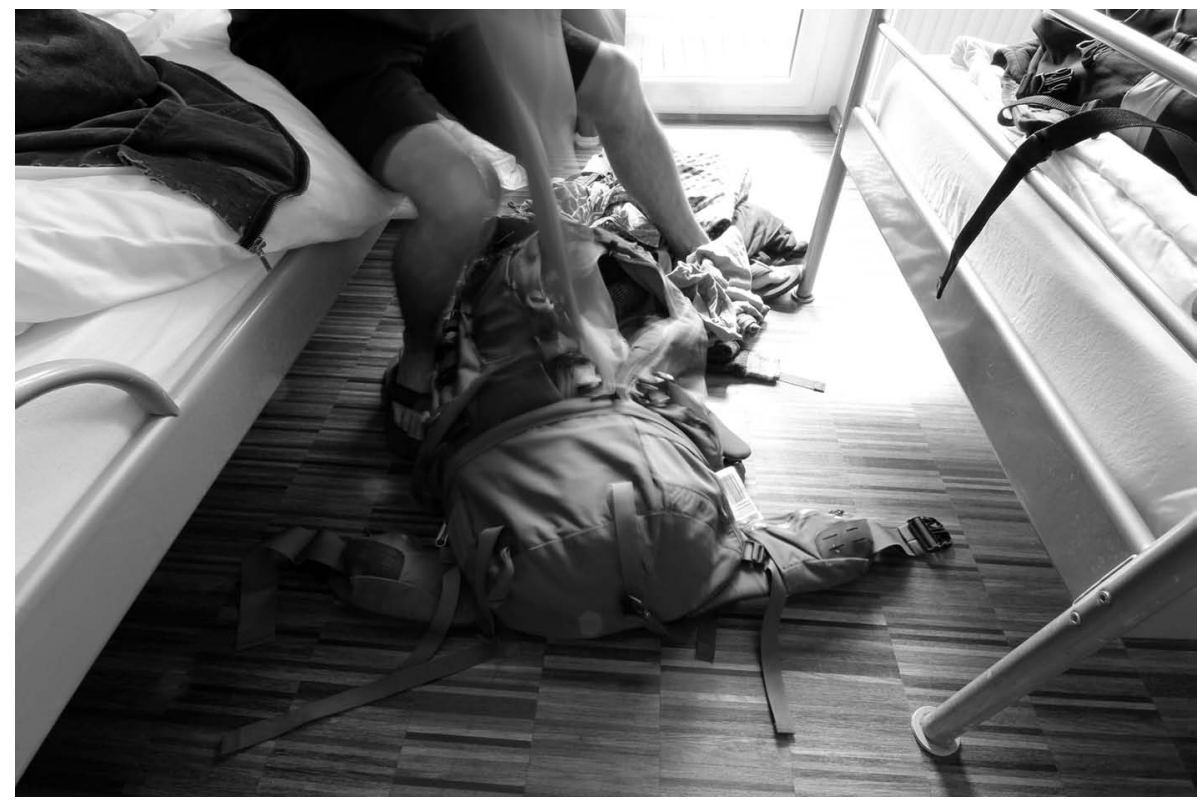

Figure 2. Rummaging among the contents of the bag. 


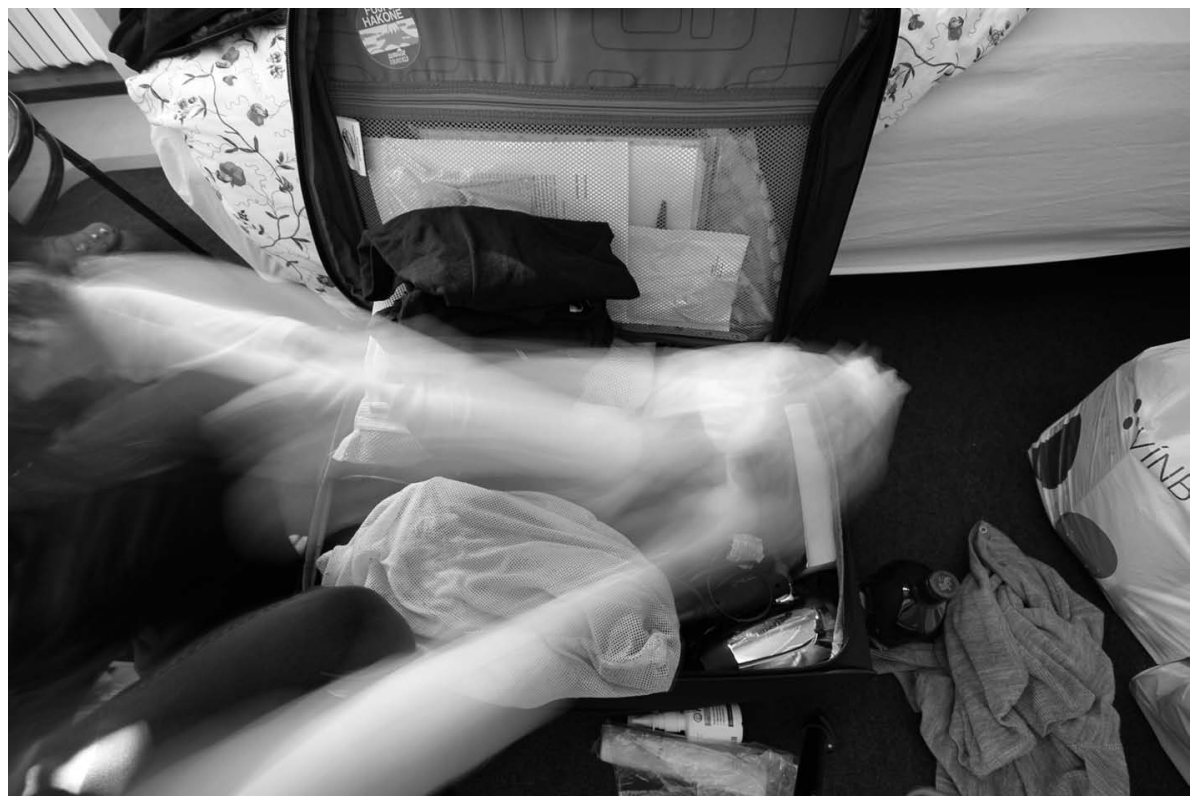

Figure 3. Arms hovering above the bag as objects are moved in and out of the bag.

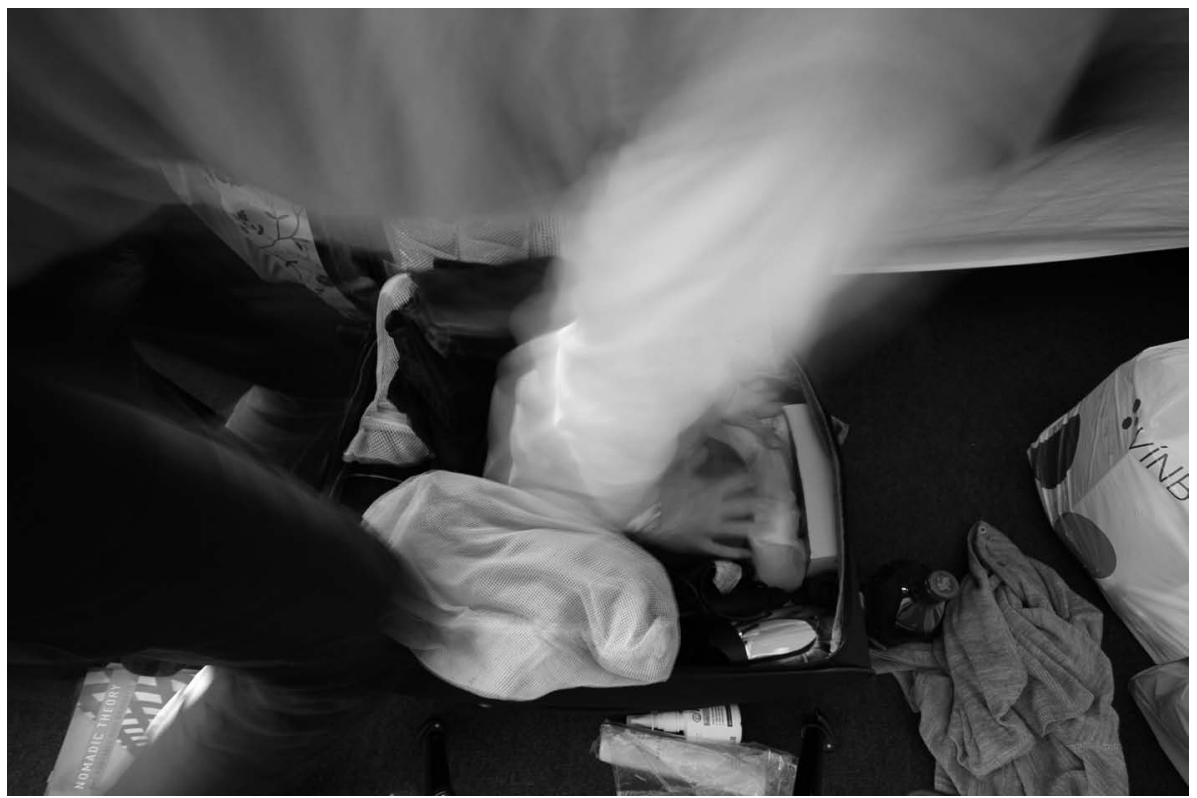

Figure 4. Kneeling and pressing on the contents of the bag. 
array of nonhuman actors and how these contribute to a collective action that is constantly unfolding in everyday procedures during travel. The many kinds of material processes in tourism, including but not isolated to the example I have given of the packing process, reflect an array of creative knowledges that present possibilities for how we situate ourselves in embodied, collaborative, and processual methods. In the instance of packing, this may arise through the manipulation of material qualities as we squish, squeeze, hold, press, or push. Alternatively, it can arise, as I outlined in the opening recollection, in assisting others in their packing. The simple act of sitting or kneeling on a bag suggests an array of interactions that arise while packing that induce collaborative and collective movements. Importantly, these simple acts point toward new methodological approaches that move beyond traditional disciplinary boundaries, harnessing both practical and theoretical engagements with tourists, tourism theories, and personal experiences.

\section{Conclusion}

The material interactions that tourists have in everyday situations raise awareness of movements and experiences that are beyond our individual actions. By overcoming disciplinary technicalities and being open to an array of practical and theoretical influences, tourists' procedures may reveal experiences that are communal and collaborative and that can be used to generate creative forms of knowledge. There is need for greater flexibility in our understandings of knowledge production (Coles et al., 2009, p. 92). To this end, I have developed the notion of creative knowledges that arise through materially driven and processual experiences in tourism that encompass an array of actors. The result is a reflexive, collective, and postdisciplinary understanding of tourist actions. Methods spanning practice and theory pave the way for inquiry-driven research (Sayer, 1999) into tourism practices and experiences, as has been advocated for some time (Coles et al., 2009).

The processes that emerge in tourism offer a glimpse into intensified intersections of bodily and material experiences that encompass an array of actors, both human and nonhuman. Tourism studies needs to take on a fluid and reflexive methodological approach willing to adapt, mould, or merge methods as we encounter an array of actors in each unique scenario. Much like the material entities are transformed into fluid, malleable substances in the packing process, the approaches we use to consider tourist practices can be approached through a wider consideration of a realm of material actors and events and may provide a basis for new forms of materially driven creative knowledges.

This examination of the process of packing has attempted to expand the understanding of packing as a touristic experience through attentiveness to the merging of practice and theory beyond traditional disciplinary boundaries. The need for a reconstitution of material relations from which creative knowledges may arise highlights the everyday processes undertaken by tourists that develop an awareness of communal actions. By making evident the vast array of actors in every movement and action, a better understanding of the collaborative nature of our everyday activities emerges, where human and nonhuman actors come into proximity and contact. The increased awareness of our material interactions reveals the extent to which we must examine our everyday experiences to determine the immersive and interconnectedness of our seemingly singular movements. In order for this to happen, the study of tourism must push forward and consider methods that, through postdisciplinary approaches, open the ways in which we may understand and participate in complex events.

Within each movement that is undertaken, the collaborative actions that tourists experience may become the basis of creative knowledge derived from moving within moments greater than themselves. This oscillation between individual-collective experience assists in understanding how we fit within a local-global culture of tourism and the implications for everyday mobilities. Teasing out these relations requires us to take into account creative knowledges and reveals how the study of tourism will benefit by engaging with creative practices and diverse theoretical approaches. New knowledge may be produced at the points where movement, action, and the boundaries of individuals and the collective meet. These relational, nomadic movements are creative and can contribute to the study of everyday life activitieswhether finding the departure gate, walking through the city, or packing a bag - that are indicative of the 
many variations of experience that our globalized culture of tourism cultivates.

\section{Note}

${ }^{1}$ This was the first fieldwork trip in my doctoral research project. The first collection of interviews was undertaken between May and July 2012 in hostels in Reykjavík (Reykjavik Downtown hostel in Iceland) and Berlin (Circus Hostel in Germany). Participants were chosen at random while I was also a guest in the hostel dormitories.

\section{References}

Barad, K. (2008). Living in a posthumanist material world: Lessons from Schrödinger's cat. In A. Smelik \& N. Lykke (Eds.), Bits of life: Feminism at the intersections of media, bioscience, and technology (pp. 165-176). Seattle: University of Washington Press.

Barrett, E., \& Bolt, B. (2007). Practice as research: Approaches to creative arts enquiry. London, UK: I.B. Tauris.

Bolt, B. (2013). Introduction: Toward a 'new materialism' for the arts. In E. Barrett \& B. Bolt (Eds.), Carnal knowledge: Towards a 'new materialism' through the arts (pp. 1-14). London, UK: I.B. Tauris.

Braidotti, R. (2002). Metamorphoses: Towards a materialist theory of becoming. Oxford, UK: Polity Press.

Braidotti, R. (2008). The politics of life as bios/zoe. In A. Smelik \& N. Lykke (Eds.), Bits of life: Feminism at the intersections of media, bioscience, and technology (pp. 177-192). Seattle, WA: University of Washington Press.

Braidotti, R. (2012). Nomadic theory: The portable Rosi Braidotti. New York, NY: Columbia University Press.

Büscher, M., \& Cruickshank, L. (2009). Designing cultures: Post-disciplinary practices. In Proceedings of the 8th European Academy of Design Conference. Retrieved from http://imagination.lancs.ac.uk/outcomes/ Designing_cultures_postdisciplinary_Practices

Carter, P. (2004). Material thinking: The theory and practice of creative research. Melbourne, Victoria, Australia: Melbourne University Press.

Coles, T., Hall, M. C., \& Duval, D. T. (2009). Post-disciplinary tourism. In J. Tribe (Ed.), Philosophical issues in tourism (pp. 80-100). Bristol, UK: Channel View.

Colman, F. (2007). Affective intensity: Art as sensorial form. In B. Bolt, F. Colman, G. Jones, \& A. Woodward (Eds.), Sensorium: Aesthetics, art, life (pp. 64-83). Newcastle, UK: Cambridge Scholars Publishing.

Crang, M. (1999). Knowing, tourism and practices of vision. In D. Crouch (Ed.), Leisure/tourism geographies: Practices and geographical knowledge (pp. 238-256). London, UK: Routledge.

Crouch, D. (2004). Tourist practice and performances. In A. Lew, C. Hall, \& A. Williams (Eds.), A companion to tourism (pp. 85-95). Malden, MA: Blackwell.

Dolphijn, R., \& van der Tuin, I. (2011). Pushing dualism to an extreme: On the philosophical impetus of a new materialism. Continental Philosophy Review, 44(4), 383-400. doi:10.1007/s11007-011-9197-2

Drummond, R., Keane, J., \& West, P. (2012). Zones of practice: Embodiment and creative arts research. M/C Journal, 15(4). Retrieved from http://journal.media-culture. org.au/index.php/mcjournal/rt/printerFriendly/528/0

Gill, A. (2012). Travelling down the road to postdisciplinary? Reflections of a tourism geographer. The Canadian Geographer/Le G'eographe canadien, 56(1), 3-17. doi:10.1111/j.1541-0064.2011.00400.x

Gregson, N. (2003). Discipline games, disciplinary games and the need for a post-disciplinary practice: Responses to Nigel Thrift's 'The Future of Geography.' Geoforum, 34(1), 5-7.

Gren, M., \& Huijbens, E. H. (2012). Tourism theory and the earth. Annals of Tourism Research, 39(1), 155-170. doi:10.1016/j.annals.2011.05.009

Grosz, E. (2005). Time travels: Feminism, nature, power. Sydney, New South Wales, Australia: Allen \& Unwin.

Grosz, E. (2011). Matter, life, and other variations. Philosophy Today, 55, 17-27.

Haldrup, M., \& Larsen, J. (2010). Material cultures of tourism. In Tourism, performance and the everyday: Consuming the Orient (pp. 58-74). London, UK: Routledge.

Hollinshead, K. (2010). Tourism studies and confined understanding: The call for a "new sense" postdisciplinary imaginary. Tourism Analysis, 15(4), 499-512. doi:10.37 27/108354210X12864727693669

Hollinshead, K., \& Ivanova, M. (2013). The multilogical imagination: Tourism studies and the imperative for postdisciplinary knowing. In M. Smith \& G. Richards (Eds.), Routledge handbook of cultural tourism (pp. 53-62). Abingdon, UK: Routledge.

Ingold, T. (2010). Footprints through the weather-world: Walking, breathing, knowing. In T. H. J. Marchand (Ed.), Making knowledge: Explorations of the indissoluble relation between mind, body, and environment (pp. 115132). Oxford, UK: Wiley-Blackwell.

Latour, B. (1996). On interobjectivity. Mind, Culture, and Activity, 3(4), 228-245. doi:10.1207/s15327884mca03 04_2

Latour, B. (2007). Reassembling the social. New York, NY: Oxford University Press.

Latour, B. (2013). An inquiry into modes of existence. Cambridge, MA: Harvard University Press.

Law, J. (2002). Aircraft stories: Decentering the object in technoscience. Durham, NCUK: Duke University Press.

Lean, G. (2012). Transformative travel: A mobilities perspective. Tourist Studies, 12(2), 151-172. doi:10.1177/1468 797612454624

Manning, E. (2009). Relationscapes. Cambridge, MA: MIT Press.

Manning, E. (2010). Always more than one: The collectivity of a life. Body \& Society, 16(1), 117-127. doi:10.1177/ $1357034 X 09354128$

Marchand, T. H. J. (2010). Introduction: Making knowledge: Explorations of indissoluble relation between mind, body, and environment. In T. H. J. Marchand 
(Ed.), Making knowledge: Explorations of the indissoluble relation between mind, body, and environment (pp. 1-20). Oxford, UK: Wiley-Blackwell.

Massumi, B. (2008). The thinking-feeling of what happens: A semblance of a conversation. Inflexions, 1(1). Retrieved from http://www.senselab.ca/inflexions/pdf/Massumi.pdf

Mol, A. (2002). The body multiple. Durham, NC: Duke University Press.

Mol, A., \& Law, J. (1994). Regions, networks and fluids: Anaemia and social topology. Social Studies of Science, 24(4), 641-671. doi:10.1177/030631279402400402

Mol, A., \& Law, J. (2007). Embodied action, enacted bodies: The example of hypoglycaemia. In R. V. Burri \& J. Dumit (Eds.), Biomedicine as culture: Instrumental practices, technoscientific knowledge, and new modes of life (pp. 87-107). London, UK: Routledge.

O’Sullivan, S. (2006). Art encounters Deleuze and Guattari: Thought beyond representation. New York, NY: Palgrave Macmillan.

Sayer, A. (1999). Long live postdisciplinary studies! Sociology and the curse of disciplinary parochialism/imperialism. Lancaster, UK: Lancaster University, Department of Sociology.
Sheller, M., \& Urry, J. (2004). Places to play, places in play. In Tourism mobilities: Places to play, places in play (pp. 1-10). London, UK: Routledge.

Thrift, N. (2007). Non-representational theory: Space, politics, affect. London, UK: Routledge.

Urry, J. (2003). Global complexity. Malden, MA: Polity Press.

Urry, J. (2012). Does mobility have a future? In M. Grieco \& J. Urry (Eds.), Mobilities: New perspectives on transport and society (pp. 3-20). Farnham, UK: Ashgate.

Urry, J., \& Larsen, J. (2011). The tourist gaze 3.0. London, UK: Sage.

van der Duim, R. (2007). Tourismscapes: An actornetwork perspective. Annals of Tourism Research, 34(4), 961-976.

van der Duim, R., Ren, C., \& Jóhannesson, G. (2013). Ordering, materiality, and multiplicity: Enacting actornetwork theory in tourism. Tourist Studies, 13(1), 3-20. doi:10.1177/1468797613476397

Wolmark, J., \& Gates-Stuart, E. (2004, April). Cultural hybrids, post-disciplinary digital practices and new research frameworks: Testing the limits. Paper presented at the Pixel Raiders 2 Conference, Australian National University, Acton, Australian Capital Territory, Australia. 